\title{
Thetford plastics fire, October 1991: the role of a preventive medical team in chemical incidents
}

\author{
Peter J Baxter, Bryan Jefferson Heap, Michael G M Rowland, Virginia S G Murray
}

\begin{abstract}
Objectives-To review the role of a medical team in the emergency management of a major polyvinyl chloride (PVC) fire in an urban area.

Methods-The district health authority's consultant in communicable disease control (CCDC) was requested to advise on the health impacts of a fire that consumed some 1000 tonnes of plastic, mainly PVC, over 72 hours and which emitted a large smoke plume that threatened the health of local residents and emergency workers alike, constituting one of the largest incidents the local emergency services had dealt with in recent years. A medical team was formed comprising the CCDC, a regional epidemiologist, an occupational physician, and a medical toxicologist. This paper is an account of this team's experience of advising on the medical management of the emergency without having any formally established role or previous training for the task.
\end{abstract}

Results-The main issues requiring the input of the medical team included: the possible products of combustion and their effects on health; the clinical management of those exposed; the alerting of local hospitals to the type of casualties to expect; the special health risks posed to emergency workers, especially the firemen; the need for evacuation of local residents; the risks of contamination of soil, water, and crops; the potential health impact of the plume; and the provision of expert and authoritative advice on the short and long term health implications to the public. Active surveillance systems, which included the local general practitioners and hospitals, were established and air monitoring instigated. The 46 casualties were restricted to emergency personnel who had inadvertently received exposure to the fire smoke: all recovered within 48 hours. Local residents were unharmed.

Conclusion-The incident showed the need for preventive medical teams trained to fill a formal advisory and investigative role for chemical releases and fires, and which can play an integral part in emergency management.
(Occup Environ Med 1995;52:694-698)

Keywords: emergency response; medical management; polyvinylchloride fire

The accidental release of toxic chemicals into the community, such as in a chemical fire or a failure of a gas storage tank, may pose acute and long term health hazards and the management of a major incident can constitute a public health emergency. In the United Kingdom a framework for the prevention of major releases from hazardous installations has been the Control of Major Accident Hazards Regulations 1984 (CIMAH), and these include the requirement for on site and off site emergency planning. ${ }^{1}$ Certain hazardous industrial activities not covered by these regulations may give rise to major incidents not anticipated by the emergency services, such as the incident we report here of a fire at a site that stored ground scrap plastic for recycling and was located adjacent to a built up area. Also, despite existing legislation and the regular involvement of the emergency services in chemical incidents, the management of major releases into the community is often inadequate and the health services in the United Kingdom are poorly prepared for dealing with chemical disasters. ${ }^{2}$ We report here our own experience of advising on the health issues that arose in this major chemical incident in which the fire raged for 72 hours over four days and constituted one of the largest incidents the local emergency services had dealt with in recent years, requiring the attendance of over 600 fire fighting personnel from four counties.

The purpose of this paper is to highlight the health issues for emergency workers and communities involved in major fire and chemical incidents, and the current deficiencies in disaster planning that prevent health professionals from participating effectively in the management of the emergency response.

\section{Report}

THE INITIAL MEDICAL RESPONSE

On the afternoon of the first day of the fire, Friday 11 October 1991, the district health authority's consultant in communicable dis- 
ease control (CCDC) was contacted by the local district chief environmental health officer to request advice on the possible medical and environmental implications of the dense smoke plume given off by a fire on a waste plastics site located in a built up part of the rural town of Thetford. The owner had reported that 1000 tonnes of scrap plastic including polyvinyl chloride (PVC), polyethylene, polypropylene, a mixture of acrylonitrile, butadiene, and styrene, and polystyrene was burning on a site covering an area of 2.6 acres. A total of 51 fire fighting appliances attended with 235 fire service personnel on the first day, and with 630 personnel attending the fire over the course of the four day incident.

The CCDC contacted the National Poisons Service and their consultant occupational toxicologist (VSGM) gave immediate advice on the possible products of combustion, their potential effects on health, and the management of those exposed. After an information and literature search more detailed information was sent by facsimile to the CCDC. The CCDC was able by that evening to provide the emergency services with this information and reinforce the requirement for those at the site of the fire to adopt appropriate protection and decontamination procedures. This information was well received and was additional to that obtained through normal industrial channels.

The CCDC informed the Accident and Emergency Department of the district hospital nearest to the fire on the type of casualties to expect and their clinical management, as advised by the National Poisons Service. The hospital was asked to record all patients complaining of symptoms after exposure to the smoke plume as this information would assist in assessing the health effects of the fire, both in the immediate and in the longer term. This request was subsequently made to all Accident and Emergency Departments in the region and hospitals were asked to plan for possible casualties should the local hospital become overwhelmed. That evening the CCDC also alerted the regional epidemiologist (MGMR) and the regional consultant occupational physician (PJB) who agreed that there was a limit to the advice that could be given without visiting the scene and that a visit should therefore be made as soon as possible. Although the medical team had no formal role, the emergency services agreed that we could attend the briefing sessions in the incident room at the local police station early next day (day 2 ). The district and regional directors of public health were kept appraised of the situation.

During the review of the incident on day 2 the emergency service personnel identified several concerns requiring urgent resolution:

- the composition and likely toxic effects of the plume

- the risk of exposure to emergency workers, especially the firemen

- the likely behaviour of the plume in different weather conditions and the area of potentially hazardous fall out

- the risk of contamination of the environment including water, vegetables, crops, and animals

- the need for evacuation of local residents

- the advice to the public at large through the media and house to house visits

Composition of the plume

In the absence of analytical information, advice from the medical team had to be initially based on the irritant and toxic substances expected to be present in the plume from combustion products of plastics. On the first two days of the fire the local department of environmental health was equipped only with gas detector tubes to measure the amount of hydrogen chloride $(\mathrm{HCl})$ present in the fumes from the burning of PVC. At the edge of the plume $\mathrm{HCl}$ was immediately identifiable in concentrations of several parts per million (ppm) in air, and high, unrecordable concentrations were found by firemen working close to the fire. On the third day the Health and Safety Executive, at the request of the medical team, extended this monitoring to include nitrogen dioxide, sulphur dioxide, hydrogen cyanide, and phosgene; in the absence of established protocols for this monitoring, air samples were taken from a variety of points around the fire and the local residential estate, and these were later reported to be negative.

\section{HEALTH EFFECTS OF THE PLUME}

On day 2 the medical team also contacted the local general practices within an estimated 10 mile radius of the fire by telephone and the on call general practitioners (GPs) were notified of the possible health hazards and clinical consequences of exposure to the smoke plume together with the recommended course of action in people thought to be affected. Respiratory symptoms associated with injury from inhalation of PVC smoke may include dyspnoea, cough, hoarseness, chest pain or tightness, wheeze, and shortness of breath. The GPs were also asked to report, on a confidential hotline manned by members of the team, any members of the public reporting problems associated with exposure to the plume, and they were invited to seek further advice on clinical management of patients if needed. General practitioners were also requested to tag the notes of any patients for future reference in case any follow up studies were considered advisable. Meanwhile two members of the medical team visited the site of the fire to assess the hazards at first hand and to observe the precautions against the smoke taken by the emergency personnel. As part of their management of the scene of the emergency, the police took sole responsibility for contacting local residents and advising them to stay indoors. Two major superstores in the vicinity were closed as a precaution.

Regular contact was maintained with the hospitals on the number and nature of casualties seen, and whether or not they required admission. Team members visited the local hospital to assess the nature and degree of exposure to which the casualties had been subjected. The casualties were almost entirely 
Frequency of symptoms in 46 emergency personnel treated at the hospital

\begin{tabular}{lc}
\hline Symptom & Affected $n$ \\
\hline Skin irritation & 22 \\
Chest tightening or dyspnoea & 18 \\
Sore throat & 8 \\
Headache & 5 \\
Cough & 6 \\
Eye irritation & 2 \\
Abdominal pain & 2 \\
Vomiting & 1 \\
Tingling hands and mouth & 1 \\
\hline
\end{tabular}

confined to fire fighters whose respiratory symptoms, if any, had arisen from only brief inhalational exposure to the smoke. This observation confirmed the impression that the smoke was highly irritant and the need to avoid exposure by all members of the public, especially those with pre-existing respiratory disease. Skin irritation was also reported in the early casualties, which reinforced advice for emergency workers to pay special attention to decontamination procedures when removing chemical suits at the scene of the fire.

A total of 46 emergency service personnel, mostly firefighters, attended the hospital as a consequence of exposure to the fire smoke (table) and four were admitted. All recovered completely within 48 hours. The main complaints were skin irritation (22/46) and breathing difficulties (18/46). A follow up of patient consultations with local general practitioners showed that after the fire only seven local residents reported symptoms to a doctor, which they felt were due to exposure to the smoke. Three patients reported tightening of the chest immediately after exposure and four reported skin irritation. A systematic clinical follow up (by the fire service occupational physician) that included lung function testing of all the firemen involved found no evidence of respiratory dysfunction or chloracne, a skin condition found in association with clinically significant exposure to dioxins, especially the isomer 2,3,7,8 tetrachlorodibenzo-P-dioxin (TCDD), which is a suspected human carcinogen and teratogen. ${ }^{3}$ Psychological trauma was unlikely in this slow burning fire.

\section{DECISION ON EVACUATION}

The decision to evacuate is the responsibility of the emergency services, who are familiar with the logistic and legal problems associated with evacuation and are understandably reluctant to invoke this measure unless it is in their view clearly necessary.

A decision was made by the senior police officer not to evacuate local residents (who numbered about 700 ) in an area $400 \mathrm{~m}$ from the fire. This was largely based on weather predictions from the Meteorological Office for the next 48 hours, which indicated that the plume would continue to be directed away from the main residential estate. In the early hours of the morning of day 3 of the fire the wind dropped and an inversion led to the plume descending on the fire site, causing the fire services to withdraw. The plume nearly enveloped the residential estate but then fortunately lifted as the emergency services were urgently reviewing the need to evacuate residents.

ENVIRONMENTAL ISSUES

During day 2 the medical team was involved in briefing, and receiving advice from, the local water service Anglian Water, the National Rivers Authority, the Ministry of Agriculture, Food and Fisheries, and the Health and Safety Executive, about the medical and environmental consequences of the fire. According to these bodies no aquifers were vulnerable to contamination by run off from the fire fighting appliances, nor was there agricultural land at risk of contamination from the fall out from the plume. We think that their assessment of health risk was strengthened by the involvement of public health, occupational health, and medical toxicology specialists.

CONCERNS OF THE GENERAL PUBLIC AND OF MEMBERS OF THE EMERGENCY SERVICES

Despite the initial reassuring findings, in the following week an independent scientist published a report stating that soil samples from the site had been found to contain increased concentrations of dioxins and "it (dioxin) is harmful to humans and is recorded to be a carcinogen, teratogen and mutagen". On the advice of the medical team, environmental samples had been obtained by the local authority and the Health and Safety Executive from both on site and off site ground areas under the plume, and these samples along with items of contaminated protective clothing were submitted to the government chemist for analysis for dioxins. When the results of this analysis became available they confirmed a 5-100 times increase of some dioxins in the on site samples above typical background soil concentrations found in the United Kingdom, but normal background concentrations were found in soil samples taken from the immediate surroundings and from under the plume. Meanwhile, concern over long term health effects was expressed by members of the emergency services, particularly fire officers who had been exposed to the plume and the local residents, and further advice was sought from the CCDC. At a meeting held several months after the event with representatives of the fire service we explained that, although an increase of on site dioxin concentrations had been shown, members of the fire service had been protected by protective clothing and respirators as well as by personal decontamination measures at the scene, and the firefighters' occupational health physician had found no evidence of health effects attributable to dioxin exposure, including chloracne. Long term follow up of the firefighters' health was not considered necessary. A press release issued jointly by the fire service and the health authority subsequently stated that the public had not received exposure to dioxins either by inhalation of smoke produced from the fire or from contamination of the off site area ground and vegetation. 


\section{Discussion}

The health risks to local populations from the plumes of fires or toxic releases depend on the chemical substances emitted and the exposure received. In acute episodes such information may be difficult to obtain, especially in fires or chemical reactions when numerous compounds can be produced and the means for collecting air samples to quantify these are not generally available. Thus decision making based on a hazards and risk assessment in such emergencies is likely to be hampered by inadequate information, even when, as in the present incident, the range of combustion and pyrolysis products are relatively well known. ${ }^{4}$

At a temperature over $300^{\circ} \mathrm{C}$ PVC decomposes to $\mathrm{HCl}$ and carbon monoxide together with small amounts of about 50 various hydrocarbons ${ }^{3-6}$; over $50 \%$ of the polymer weight may come off as $\mathrm{HCl}$ gas. Phosgene is produced only in rare circumstances and the quantity of dioxin formed is likely to be not clinically significant. Acrylonytrile, butadiene, and styrene were also present and would be expected to emit hydrogen cyanide in the smoke. $^{5}$ Various other respiratory irritants such as acrolein, ammonia, $\mathrm{SO}_{2}, \mathrm{NO}_{2}$, aldehydes, and particulates may be found in fire smoke. ${ }^{4}$ Although the presence of $\mathrm{SO}_{2}$ is dependent on significant amounts of sulphur compounds being present in the "fuel", nitrogen oxides formed from nitrogen and oxygen in the air are always found in fire smoke. Plastics also contain additives of complex organic molecules including heavy metal salts - for example, cadmium, lead, and titanium-for ultraviolet stabilisation, antistatic properties, and colouring.

The $\mathrm{HCl}$ concentrations are said to rapidly decline in fires, but the large mass of plastic waste involved here resulted in a smouldering fire that lasted for 72 hours despite the efforts of the fire services to extinguish it with water. Large plastics fires are notoriously difficult to extinguish because of the formation of a plastic skin that prevents water getting to the heart of the fire. Hydrogen chloride was therefore likely to have been emitted for much of the time the fire continued.

Toxicological studies suggest that the irritancy of PVC combustion products is similar to that of $\mathrm{HCl}^{4}{ }^{4}$ The clinical impression gained from the effects on the fire fighters who were seen at the hospital suggested that the irritancy of the smoke was greater than would be accounted for by $\mathrm{HCl}$ alone. Relatively few studies of exposure to $\mathrm{HCl}$ have been undertaken in human volunteers, including people with asthma, but concentrations of $1-10 \mathrm{ppm}$ are thought to be well tolerated by healthy adults and the life threatening concentrations are probably in the range of 1300-2000 ppm for a few minutes with death being caused by laryngeal or pulmonary oedema. ${ }^{78}$ The main respiratory irritant effect of $\mathrm{HCl}$ is on the upper airways where it will be scrubbed from the inspired air because of its hygroscopicity and reactivity and it is 30 times less irritant than chlorine. No major incidents involving the public have been recorded as a conse- quence of releases of $\mathrm{HCl} .^{9}$ The risk assessment must take into account the products of a fire that are not a single chemical such as $\mathrm{HCl}$ but a mixture of chemicals the effects of which may be potentiated in fire smoke.

Thus according to a study of fire fighters exposed to PVC smoke the range of symptoms was wider than would be experienced from exposure to $\mathrm{HCl}$ alone ${ }^{10}$ and symptoms of asthma or bronchitis may become persistent, ${ }^{11}$ but the lack of information on the effects of low levels of $\mathrm{HCl}$ on susceptible people such as those with asthma ${ }^{8}$ makes the assessment of risk of PVC fires extremely difficult. Such incidents should be regarded as chemical releases of substantially greater toxicity than fire smoke alone, and an analogy with an uncontrolled emission of $\mathrm{HCl}$ gas from a chemical plant, as in a major chemical accident, would be more appropriate.

Communities can be exposed to health hazards from the plumes of fires in the form of particle fallout as well as direct fumigation from plumes as they expand by diffusion or are driven to ground level by cooling, wind, or thermal inversions. Plumes from the oil fires in Kuwait after the Gulf War were convected away from populated areas by the intense heat, but they nevertheless posed a potential health hazard from particle fallout that included elemental carbon, metal oxides, silicates, vanadium, nickel, and polycyclic aromatic hydrocarbons. ${ }^{12}$ In contrast, the plume from the Sandoz chemical warehouse fire in 1986 fumigated parts of Basle city at night, potentially exposing thousands of people to an unknown mixture of chemical combustion and reaction products. ${ }^{13}$

In the present fire the development of an inversion in the early hours of the second morning had not been anticipated, and we conclude that the risk from a large fire to a nearby population may change unexpectedly depending upon the state of the fire and the local weather conditions. Thus decisions on evacuation should be made early on to ensure that people can be moved at a time when conditions are most favourable.

The decision to evacuate all or part of a community can be a complex and daunting one for the emergency services. Unless clear guidance on evacuation is available advice is likely to be needed from a range of specialists if time permits for such consultations, as in this example. In brief, chemical releases that leave no residual contamination-for example, an escape of a toxic gas such as chlorine, the most appropriate option is usually to rely on the protection afforded by buildings with their doors, windows, and ventilation systems closed, so long as the occupants go outside as soon as the plume has passed. ${ }^{14}$ With prolonged incidents evacuation may be more advisable for the reasons already stated. With preliminary information the medical team at the scene was in a position to advise the emergency services on the likely health effects of exposure to $\mathrm{HCl}$, the main toxic irritant in PVC fires, especially in elderly people and in people with asthma and chronic bronchitis, 
and to indicate that these effects could be even more dangerous than those from exposure to smoke from conventional fires, although temporary protection could be obtained by breathing through a wet cloth as the gas is highly soluble in water.

In all chemical releases longer term hazards such as carcinogenicity or teratogenicity should be considered from the outset-for example, if there is a risk of ground contamination from dioxins produced in reactions in the heat of a chemical fire, or from asbestos from the destruction of buildings (which was not a consideration here). There is growing evidence that large fires involving PVC may release substantial quantities of dioxins into the United Kingdom environment compared with annual inputs from all identified emissions. ${ }^{15}$ Also health surveillance of the local population for the early detection of any unanticipated health manifestations, including stress disorders, should be rapidly established. We did this through a telephone network of family practitioners and hospitals.

Our experience at this incident has highlighted the value of a multidisciplinary approach that involved not only public health physicians with epidemiological expertise but also medical toxicologists and occupational physicians, who can work alongside the emergency services at the scene. ${ }^{16}$ Other professionals will also be needed, especially occupational hygienists and environmental specialists with the capability of doing emergency air and environmental sampling. Assessment of the health risks is a complex task that includes the identification of the chemical agents involved, compiling toxicological data, rapidly collating information on health effects in the exposed population, attempting to quantify exposure, assessing dose-response relations through short or long term epidemiological studies, and characterising the health risk at different stages as the incident unfolds. This evaluation is needed not only for the emergency management of the incident but also for the medical management of any casualties, particularly in accidents that involve exposure of whole communities as knowledge of the toxic effects of even common chemicals in these events is sparse.

The community may perceive any chemical release as a major health threat, despite lack of any evidence of acute damage to health or to the environment, as was the case here when reports of possible contamination of the site and its immediate surroundings by dioxin raised public alarm. The public health physi- cian must be able to speak clearly and authoritatively on such concerns and this is only possible through an adequate assessment of the health risks made possible by a pre-planned and co-ordinated response to the emergency. Preparation for response to major chemical incidents must be a part of emergency planning and involve all the emergency services and include the active participation of the health sector. ${ }^{17}$ The recognition of this by the Department of Health in its guidelines for planning for chemical incidents ${ }^{18}$ is welcome and now needs to be followed by specific guidance and training to equip physicians for this role.

We are indebted to the many emergency workers involved in this incident for their collaboration. We thank Dr Keith Cassidy and his colleagues at the Health and Safety Executive, Dr David Purser at the Fire Research Station, and Ms Heather Wiseman for their comments on an early draft of this paper, and Mr Bryan Smith, chief fire officer of the Norfolk Fire and Mr Bryan Smith, chief fire officer of the Norfolk Fire Service, and Mr Donald John chief environmental health offiDr James Hilton kindly provided information on the health of Dr James $H$
the firemen.

1 Health and Safety Executive. The control of major industrial accident hazards regulations 1984 (CIMAH): further guidance on emergency plans. London: HMSO, 1986.

2 Baxter PJ. Major chemical disasters. BMf 1991;302:61-2.

3 Raffle PAB, Adams PH, Baxter PJ, Lee WR, eds. Hunter's diseases of occupations, 8th ed. London: Edward Arnold, 1994.

4 Doe JE. The combustion toxicology of polyvinylchloride revisited. fournal of Fire Sciences 1987;5:228-47.

5 Terrill JB, Montgomery RR, Reinhardt CF. Toxic gases from fires. Science 1978;217:21-3.

6 Hirschler M. The hazards of PVC. Fire Prevention 1989;217:21-3.

7 Kamrin MA. Workshop on the health effects of $\mathrm{HCl}$ in ambient air. Regul Toxicol Pharmacol 1992;15:73-82.

8 Stevens B, Koenig JQ, Rebolledo V, Hanley QS, Covert DS. Respiratory effects from the inhalation of $\mathrm{HCl}$ in young adult asthmatics. F Occup Med 1992;34:923-9.

9 World Health Organization. Chlorine and $\mathrm{HCl}$. Geneva: WHO, 1982. (Environmental Health Criteria 21.)

10 Markowitz JS, Gutterman EM, Schwartz S, Link B, Gorman SM. Acute health effects among firefighters exposed to a polyvinyl (PVC) fire. Am f Epidemiol 1989;129:1023-31.

11 Markowitz JS. Self Reported short- and long-term respiratory effects among PVC exposed firefighters. Arch Environ Health 1989;44:30-3.

12 Al-Shatti AKS, Harrington JM, eds. The Environmental and health impact of the Kuwaiti oil fires. Birmingham: University of Birmingham, 1992.

13 Ackerman-Leibrich UA, Braun C, Rapp RC. Epidemiological analysis of an environmental disaster: the Schweizerhalle experience. Environ Res 1992;58:1-14

14 Purdy G, Davies PC. Toxic gas incidents-some important considerations for emergency planning. In: the assessment and control of major hazards. Rugby: Institute of Chemical Engineers, 1985:367-88.

15 Meharg AA, Osborn D. Dioxins release from chemical accidents. Nature 1995;375:353-4.

16 Baxter PJ. Review of major chemical accidents and their medical management. In: Murray V, ed. Major chemical disasters: medical aspects of management. London: Royal Society of Medicine, 1990:7-20.

17 Organisation for Economic Cooperation and Development. Health aspects of chemical accidents. Paris: OECD, 1994. Health aspects of chemical accidents.

18 NHS Management Executive. Health Service guidelines. Arrangements to deal with health aspects of chemical contamination incidents. London: Department of Health, 1993. (HSG(93)38.) 